\title{
Reduced Susceptibility to Xanthomonas citri in Transgenic Citrus Expressing the FLS2 Receptor From Nicotiana benthamiana
}

\author{
Guixia Hao, Marco Pitino, Yongping Duan, and Ed Stover \\ U. S. Horticultural Research Laboratory, USDA-ARS, Fort Pierce, FL 34945, U.S.A. \\ Submitted 17 September 2015. Accepted 6 November 2015.
}

\begin{abstract}
Overexpression of plant pattern-recognition receptors by genetic engineering provides a novel approach to enhance plant immunity and broad-spectrum disease resistance. Citrus canker disease associated with Xanthomonas citri is one of the most important diseases damaging citrus production worldwide. In this study, we cloned the FLS2 gene from Nicotiana benthamiana cDNA and inserted it into the binary vector pBinPlus/ARS to transform Hamlin sweet orange and Carrizo citrange. Transgene presence was confirmed by polymerase chain reaction (PCR) and gene expression of $\mathrm{NbFLS2}$ was compared by reverse transcription quantitative PCR. Reactive oxygen species (ROS) production in response to flg22 $2_{X c c}$ was detected in transgenic Hamlin but not in nontransformed controls. Low or no ROS production was detected from nontransformed Hamlin seedlings challenged with flg22 ${ }_{X c c}$. Transgenic plants highly expressing NbFLS2 were selected and were evaluated for resistance to canker incited by $X$. citri 3213. Our results showed that the integration and expression of the $\mathrm{NbFLS2}$ gene in citrus can increase canker resistance and defenseassociated gene expression when challenged with $X$. citri. These results suggest that canker-susceptible Citrus genotypes lack strong basal defense induced by $X$. citri flagellin and the resistance of these genotypes can be enhanced by transgenic expression of the flagellin receptor from a resistant species.
\end{abstract}

Plants use pattern-recognition receptors to detect potential pathogens by recognizing pathogen-associated molecular patterns (PAMPs) and eliciting PAMP-triggered immunity (PTI) against pathogen growth and disease development. PTI is associated with PAMP recognition and activation of plant plasma membrane receptors (Gómez-Gómez et al. 2001; Jones and Dangl 2006). PAMPs such as bacterial flagellin are largely conserved across a wide range of bacteria, as these molecules are essential for motility and movement. Perception of bacterial flagellin by AtFLS2 (flagellin sensing 2) in Arabidopsis thaliana is well studied and the conserved peptide flg22 induces the expression of many defense-related genes (Zipfel et al. 2004). FLS2 interacts with the receptor kinase BAK1 by forming a functional FLS2/BAK1 complex, which is subsequently followed by calcium ions $\left(\mathrm{Ca}^{2+}\right)$ influx, reactive oxygen species (ROS) production, and

Corresponding authors: Ed Stover; Telephone: +1.772 .462 .5951 ; Fax: +1.772.462.5986; E-mail: ed.stover@ars.usda.gov; and Guixia Hao; Telephone: +1.772 .462 .5975 ; Fax: +1.772 .462 .5986 ; E-mail: guixia. hao@ars.usda.gov

*The $\boldsymbol{e}$-Xtra logo stands for "electronic extra" and indicates that five supplementary figures are published online.

() 2016 The American Phytopathological Society mitogen-activated protein kinase (MAPK) pathway activation (Gómez-Gómez et al. 2001; Jones and Dangl 2006).

Mutagenesis and crystal structure studies on AtFLS2 A. thaliana revealed that some amino acids, including 366T, $392 \mathrm{H}$, and 414D in the extracellular leucine-rich repeat (LRR) domain and $1064 \mathrm{G}$ in the kinase domain, are essential for binding to flg22 (Dunning et al. 2007; Gómez-Gómez et al. 2001; Sun et al. 2013). FLS2 from different plant species have specificities that permit recognition of flagellin peptides from different bacterial species (Chinchilla et al. 2006; Robatzek et al. 2007). SIFLS2 from tomato (Solanum lycopersicum) and NbFLS2 from $N$. benthamiana can perceive the 22 and 15 amino-acid peptides derived from Pseudomonas syringae flagellin; however, SIFLS2 but not NbFLS2 can recognize the 15 amino-acid peptide derived from Escherichia coli flagellin (Robatzek et al. 2007). AtFLS2 and SIFLS2 have been shown to exhibit species-specific differences in the recognition of shortened or modified flg22 ligands through domain-swapping studies (Mueller et al. 2012). OsFLS2 from rice (Oryza sativa) was discovered to be responsive only to a specific flagellin from the incompatible strain $P$. avenae (Che et al. 2000; Felix et al. 1999). VvFLS2 from grapevine (Vitis vinifera) has been shown to differentially recognize flg22 epitopes from a growth-promoting bacterium and plant-pathogenic bacteria (Takai et al. 2008). Though FLS2 orthologs from different plants have specificities in recognition of specific bacterial flagellins, some bacterial flagellins are widely perceived by FLS2 orthologs characterized from different plant species, including rice (OsFLS2), $N$. benthamiana (NbFLS2), tomato (SIFLS2), and grapevine (VvFLS2) (Chakravarthy et al. 2010; Robatzek et al. 2007; Takai et al. 2008; Trdá et al. 2014). It has been reported that VvFLS2 from grapevine can complement $A$. thaliana fls 2 mutant function and AtFLS2 from A. thaliana is functional in transgenic tobacco (Trdá et al. 2014; Robatzek et al. 2007).

Citrus canker associated with $X$. citri is one of the most important diseases affecting citrus production worldwide, leading to yield losses, poor fruit quality, and trade barriers. The disease affects leaves, stems, and fruits, and symptoms consist of roughly circular water-soaked lesions that cause defoliation, dieback, and fruit drop (Brunings and Gabriel 2003). Many commercial citrus varieties, including sweet orange [Citrus sinensis (L.) Osbeck], grapefruit (C. paradisi Macf), and lemon [C. limon (L.) Burm. f.], are susceptible to canker disease (Gottwald et al. 1993). Recently, the susceptible citrus genotypes 'Duncan' grapefruit and 'Navel' sweet orange have been shown to have no significant ROS production or PTI/effector-triggered immunity-associated gene induction following flg22 $2_{X c}$ treatment (Shi et al. 2014). In contrast, resistant genotypes such as 'Nagami' kumquat and 'Sun Chu Sha' mandarin show higher ROS production following flg $22_{X c c}$ treatment (Shi et al. 2014). 
Genetic engineering is a promising strategy to complement classical citrus breeding and enhance disease resistance for susceptible commercial varieties. Several resistance $(R)$ genes have been transgenically introduced into plants for disease control. The $B s 2$ pepper gene conferred resistance to bacterial spot disease when expressed in tomato (Tai et al. 1999). Transgenic tobacco expressing the tomato gene Pto showed enhanced resistance to disease incited by Pseudomonas syringae pv. tabaci (Thilmony et al. 1995). However, $R$ geneinduced resistance provides resistance only to particular pathogen strains and rarely confers broad-spectrum disease resistance (McDonald and Linde 2002). In addition, it is easily overcome by pathogens via mutation or gene transfer to acquire new effectors that counteract plant resistance (Leach et al. 2001).

Overexpression of PAMP receptors has been proposed as a way to enhance disease resistance in transgenic plants. Strong immune response was induced by flagellin and flg22 in transgenic rice through overexpression of OsFLS2; however, no increased disease resistance was observed when infiltrated with bacteria (Takai et al. 2008). The bacterial elongation factor Tu (EF-Tu) is recognized by the EF-Tu receptors (EFR) from Brassicaceae and Solanaceae species and some rice cultivars (Boller and Felix 2009). It has been demonstrated that transgenic expression of EFR from A. thaliana conferred responsiveness to bacterial EF-Tu in $N$. benthamiana and tomato, enhancing disease resistance to a range of phytopathogenic bacteria from different genera (Lacombe et al. 2010). In addition, expression of rice $X A 21$ in sweet orange, tomato, and banana enhanced resistance to $X$. citri, Ralstonia solanacearum, and $X$. campestris pv. musacearum, respectively (Afroz et al. 2011; Mendes et al. 2010; Tripathi et al. 2014). Heterologous expression of these PAMPs has been proven to enhance broadspectrum disease resistance through strengthening the plants' own innate immune system. We have previously reported that Agrobacterium-mediated transient expression of flagellin from 'Candidatus Liberibacter asiaticus' and ' $\mathrm{Ca}$. L. solanacearum' in $N$. benthamiana is sufficient to induce ROS production and PTI-associated gene expression (Hao et al. 2014; Zou et al. 2012). Compared with flg22 Las and flg22 $2_{\text {Lso }}$, flg22 $2_{c c}$ can induce PAMP-associated gene expression at a much lower concentration and elicit a stronger cell-death response following transient expression in $N$. benthamiana (Chinchilla et al. 2006; Zou et al. 2012). Hamlin sweet orange (C. sinensis (L.) Osbeck) is one of the most important citrus scion cultivars in Florida and is very susceptible to canker disease. Carrizo citrange (Citrus sinensis L. Osbeck $\times$ Poncirus trifoliata L.) is an important rootstock and is also susceptible to canker. In the present study, we transgenically expressed NbFLS2 in Hamlin and Carrizo. We determined that ROS production was significantly induced in transgenic citrus exposed to flg $22_{X c c}$. We showed that transgenic citrus plants with high expression levels of $N b F L S 2$ displayed enhanced disease resistance to citrus canker via improving plant basal defense through interaction of bacterial flagellin and NbFLS2. We demonstrated that the PTI marker gene WRKY22 and defenserelated gene $P R l$ were also activated in transgenic citrus plants carrying highly expressed $N b F L S 2$ after exposure to $X$. citri.

\section{RESULTS}

\section{Hamlin and Carrizo citrus plants transformed with $N b F L S 2$.}

A full-length $N b F L S 2$ coding sequence was amplified from cDNA and was inserted into pBinPlus/ARS transcribed from a double $35 \mathrm{~S}$ promoter. A total of 17 independent kanamycinresistant Hamlin plants were obtained by Agrobacteriummediated transformation. Polymerase chain reaction (PCR) primers NbFLS2-For and Nos-Rev (Table 1), located in $N b F L S 2$ and the Nos terminator of pBinPlus/ARS, were used for PCR amplification. Ten of these plants were shown to contain the NbFLS2 transgene (Supplementary Fig. S1A). Similarly, over 30 transgenic Carrizo plants were confirmed to contain the NbFLS2 gene. The PCR-positive NbFLS2 plants were further evaluated.

\section{Difference in transgene expression \\ among the transgenic citrus plants.}

RNA from the NbFLS2-positive transgenic plants was isolated and amplified by conventional reverse transcription PCR (RT-PCR), confirming transgene transcription in these plants (data not shown). The relative levels of transcription in these

Table 1. Primers used in this study

\begin{tabular}{|c|c|c|}
\hline Gene name & Primer sequence & Amplicon size (bp) \\
\hline \multicolumn{3}{|l|}{ For transgenic plants } \\
\hline NbFLS2-For & TCAAATGGTGGATGACTGGA & 930 \\
\hline Nos-Rev & TTTGCGCGCTATATTTTGTTT & \\
\hline \multicolumn{3}{|l|}{ For $N b F L S 2$ cloning } \\
\hline NbFLS2-ORF-For & TCTCCCGGGGAACCAACAATGTCACAGACAG & 3,500 \\
\hline NbFLS2-ORF-Rev & TCGACTAGTTCAAATTGCATCGTTTACCAAACAAG & \\
\hline \multicolumn{3}{|c|}{ For gene expression by real time polymerase chain reaction } \\
\hline NbFLS2-RT-5' & GGAGAAAGGGAACTTGGACAATA & 97 \\
\hline NbFLS2-RT-3' & ACCACTAGCAACCGAAACTAAA & \\
\hline CsFLS2-RT-5' & CAGGACTGGATGAAGAGAATGG & 110 \\
\hline CsFLS2-RT-3' & CAGCCTAGGGTCTGTGATTTG & \\
\hline CsFLS2-L-RT-5' & CAACCAACATCAGTCCACAATAAG & 103 \\
\hline CsFLS2-L-RT-3' & CAAAGAGGGTGACTACAGCTATC & \\
\hline CsPRl-RT-5' & ACAAACACACATCTCCGAAATGA & 100 \\
\hline CsPR1-RT-3' & TTGAAATGAGCAGCAGCAAAA & \\
\hline CsGST1-RT-5' & TCAAGGGCAATCACCCAATAC & 106 \\
\hline CsGST1-RT-3' & ССАССТССТТССАТАССААТААС & \\
\hline CsWRKY22-RT-5' & GGCCTAAGCTTTCCGATTCT & 97 \\
\hline CsWRKY22-RT-3' & GTCACCCTTTGCACTACTCTT & \\
\hline CsGAPC2-RT-5' & TCTTGCCTGCTTTGAATGGA & 80 \\
\hline CsGAPC2-RT-3' & TGTGAGGTCAACCACTGCGACAT & \\
\hline \multicolumn{3}{|c|}{ For bacterial growth by pthA detection } \\
\hline VM3 & GCATTTGATGACGCCATGAC & 151 \\
\hline VM4 & TCCCTGATGCCTGGAGGATA & \\
\hline
\end{tabular}


plants were compared by RT-quantitative (q)PCR, and highly variable expression was observed. In particular, transgenic Hamlin plants H5, H6, and H16 displayed high transcription levels, while transgenic plants $\mathrm{H} 2, \mathrm{H} 10, \mathrm{H} 13$, and $\mathrm{H} 17$ showed low transcription levels (Fig. 1A). The absence of NbFLS2 mRNA in transgenic plant H12 may be due to transgene insertion position or gene silencing. Similarly, conventional RT-PCR and real time qPCR were performed to compare gene expression in transgenic Carrizo plants. Transgenic Carrizo plants C11, C51, C57, and C66 showed high NbFLS2 expression level while C35 and C38 have relatively low expression levels (Fig. 1B).

\section{Characteristics of citrus FLS2 orthologs and their expression in nontransformed and $N b F L S 2$ transgenic citrus plants.}

To identify FLS2 orthologs in citrus, a blast search was performed against the NbFLS2 protein (Joint Genome Institute [JGI] Phytozome database and the National Center for Biotechnology Information [NCBI]). Two citrus FLS2 orthologs were identified from Valencia sweet orange using the NCBI database, which showed high homology (99\%) with FLS2 homologs from C. clementina (JGI Phytozome database), and one of them was designated as CsFLS2. Gene CsFLS2 encodes a protein with 1,194 amino acids sharing 54\% identity with A. thaliana AtFLS2 and $61 \%$ identity with $N$. benthamiana NbFLS2 (Supplementary Fig. S2). A blast search of $C$. sinensis sequences from the JGI Phytozome database using NbFLS2 showed several candidates that shared significantly lower identity (35\%) with AtFLS2 from Arabidopsis and NbFLS2 from $N$. benthamiana. One of them (orange1.1 g000859m) encodes 1,251 amino acids and was designated as CsFLS2-like (CsFLS2-L) for further analysis. Sequence alignment analysis showed CsFLS2 shares the typical FLS2 LRR-RK structure. The LRR domain of CsFLS2 consists of 28 LRR tandem repeats, similar to AtFLS2 and LeFLS2. In contrast, the LRR domain of CsFLS2-L consists of 31 LRR tandem repeats with highly variable sequences. It is noteworthy that CsFLS2 shares all the critical amino acids for FLS2 function, while CsFLS2-L contains only some of them. Phylogenic analysis showed that the CsFLS2 protein is in the same cluster with FLS2 homologs from poplar and $V$. vinifera with a high level of confidence. CsFLS2-L was shown to be somewhat more distantly associated with the other genes in the phylogenic tree (Fig. 2).These data suggest that CsFLS2 is a promising FLS2 ortholog and CsFLS2-L may or may not be a FLS2 ortholog.

To investigate citrus $F L S 2$ ortholog expression in transgenic plants expressing $N b F L S 2$ and control plants, primers were designed in the unique regions of $N b F L S 2, C s F L S 2$, and CsFLS2-L (Table 1). RT-qPCR indicated low levels of expression for CsFLS2 and CsFLS2-L compared with NbFLS2 in Hamlin and Carrizo transgenic plants with native gene expression similar to nontransgenic control plants (Supplementary Fig. S3). The transgenic plants showed normal leaf morphology and overall appearance.

\section{High ROS production induced in some of the transgenic citrus.}

To test whether nontransgenic Hamlin can produce ROS response to flg $22_{X c c}$, leaves from over 40 2-month-old Hamlin seedlings were tested and no marked ROS production was detected in most of them, with relatively low ROS production observed from two seedlings (Fig. 3A). In contrast, transgenic Hamlin plants displayed ROS production in response to flg $22_{X c c}$ that ranged up to 14-fold that of the nontransformed Hamlin control. Transgenic Hamlin plant FLS2-H5 showed the highest levels of ROS production, and transgenic plants FLS2$\mathrm{H} 6$ and $\mathrm{H} 10$ showed intermediate levels (Figs. 3C and 4A), and ROS production correlated with the NbFLS2 expression levels in these transgenic plants. These results suggest that FLS2 receptors from sweet orange poorly recognize the $X$. citri flagellin peptide, even though $C s F L S 2$ and $C s F L S 2-L$ RNA were detected in transgenic and nontransgenic plants. In part, this may result from CsFLS2-L showing low homology with known
A

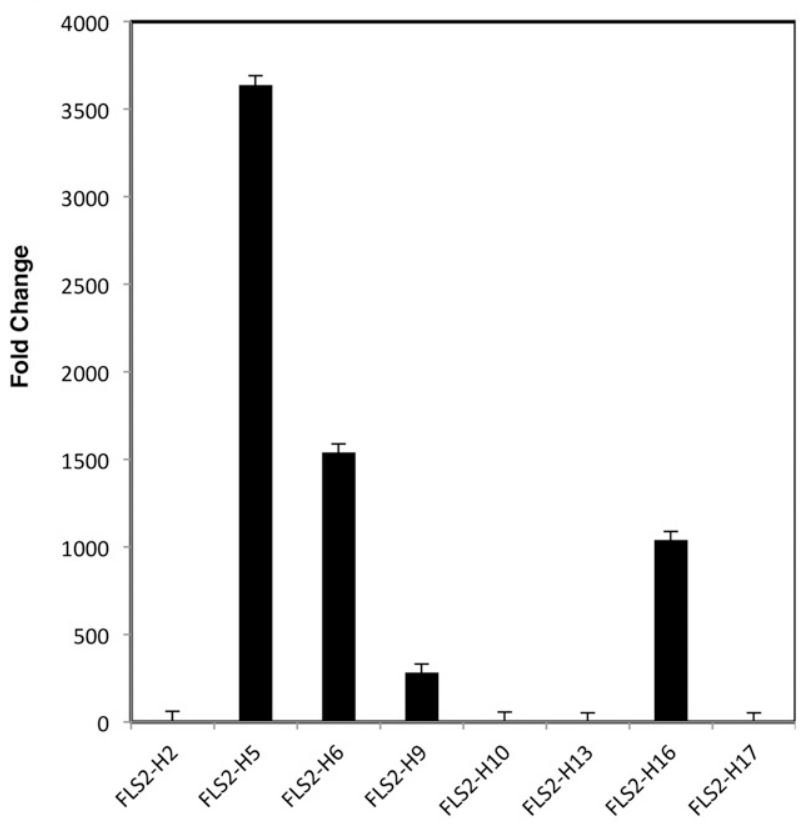

NbFLS2 expression in Hamlin transgenic lines
B

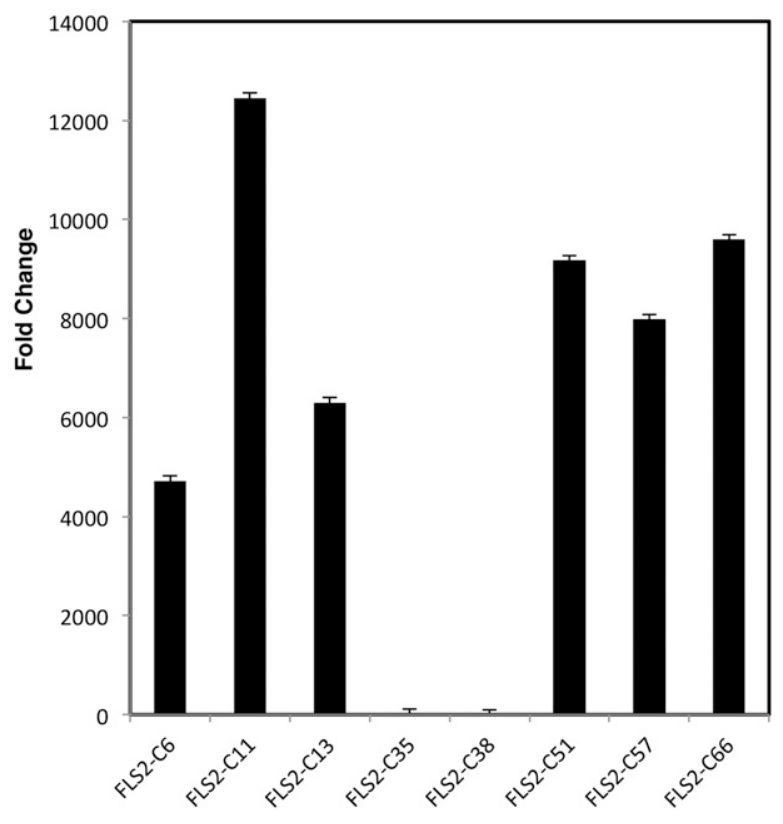

NbFLS2 expression in Carrizo transgenic lines

Fig. 1. Gene expression in citrus. A, Transgenic Hamlin expression of $N b F L S 2$ and $\mathbf{B}$, transgenic Carrizo expression of $N b F L S 2$. Expression fold change is relative to the lowest $N b F L S 2$ expression tested, which was used as a calibrator due to its low abundance. 
functional FLS2 receptors and lacking critical amino acids essential for FLS2 function.

A total of 20 nontransgenic Carrizo seedlings were also tested for ROS response. Somewhat higher peak ROS production was produced from a few Carrizo seedlings compared with the Hamlin seedlings; however, no marked ROS was detected in most Carrizo seedlings and transgenic Carrizo had much higher ROS production (Fig. 3). Compared with transgenic Hamlin, higher ROS production was detected from transgenic Carrizo plants (Fig. 3D), which may reflect a contribution from greater Carrizo basal response, also reflected by somewhat higher ROS production in nontransgenic seedlings (Fig. 3B). One ROS peak was detected in most of the Carrizo transgenic plants. However, two ROS peaks were repeatedly detected from transformed Carrizo plant C57 (Fig. 4B). A typical ROS peak was initiated about 5 min after treatment with flg $22_{X c c}$ and returned to the basal level after 35 mins. However, in transgenic plant $\mathrm{C} 57$, before ROS production returned to the basal level, a second ROS peak began 28 min after treatment with flg22 $2_{X c c}$ (Fig. 4B). Overall, these data suggest that FLS2 orthologs in sweet orange and Carrizo interact weakly with $X$. citri flagellin. In contrast, transgenic expression of $N b F L S 2$ activated a strong ROS response involving the citrus PTI pathway. This weak to nonexistent response from native FLS2 orthologs may result in high susceptibility of Hamlin and Carrizo to citrus canker caused by $X$. citri.

\section{Reduced susceptibility to $X$. citri in the transgenic citrus with high ROS.}

To determine whether the NbFLS2 transgene influences the susceptibility of sweet orange cultivars to $X$. citri, eight independent transgenic Hamlin plants and 10 independent transgenic Carrizo plants were inoculated with the pathogen. Several nontransformed plants and FLS2 PCR-negative plants of each cultivar were used as controls. The effectiveness of the transgene in reducing disease development was not significant with infiltration at the concentration of $10^{7}$ or $10^{6} \mathrm{CFU}$ per milliliter. Slightly reduced canker symptoms were shown in transgenic citrus with lower titer infiltration $\left(10^{4}\right.$ or $10^{3} \mathrm{CFU}$ per milliliter) (Supplementary Fig. S4). X. citri growth was also assessed at various time points after leaf infiltration at $10^{6} \mathrm{CFU}$ per milliliter in transgenic plants and nontransgenic control. No obvious $X$. citri growth difference was observed between transgenic and nontransgenic leaf disc samples collected at $0,3,6$, 9 , and 12 day after inoculation (dai) (data not shown). Therefore, leaf disc samples were taken at $2 \mathrm{~h}, 1,2,3,5$, and 7 dai in a second experiment. Bacterial population decreased at 1 dai in Hamlin transgenic plants H5 and H6 (Supplementary Fig. S5), but growth resumed and was not obviously different from controls. However, with spray inoculation at $10^{6} \mathrm{CFU}$ per milliliter, transgenic plants with high ROS production and high NbFLS2 expression showed marked disease resistance 4 weeks after inoculation (Fig. 5A and D). Furthermore, canker lesion development was greatly reduced in Hamlin transgenic plants $\mathrm{H} 5$ and $\mathrm{H} 6$ and Carrizo transgenic plant $\mathrm{C} 11$ compared with other transgenic plants and control plants (Fig. 5E and F). With spray inoculation, all tested transgenic Hamlin and Carrizo expressing NbFLS2 showed reduced canker development as compared with control plants. Based on statistical analysis by one-way analysis of variance and Tukey's-B posttest, the canker lesion development level is significantly less in transgenic plant expressing NbFLS2 than in control plants (Fig. 6).

To further investigate whether PTI or defense-associated gene expression was affected after $X$. citri challenge, WRKY22, and GST1 expression, which were induced in Arabidopsis and citrus with flg22 treatment, were investigated as markers of PTI (Asai et al. 2002; Shi et al. 2014). PRl gene expression, which is a marker for salicylic acid (SA)-mediated resistance, was also examined in our study. Without $X$. citri challenge, the expression of $C s W R K Y 22$, CsGST1, or CsPR1 was very low with no significant difference between negative controls or transgenic plants with low (FLS2-H12 and H14) or high (FLS2H5 and H6) NbFLS2 expression (Fig. 7A). These results suggest that ectopic expression of $N b F L S 2$ does not induce chronic expression of plant immunity and defense-associated genes. The expression of CsGST1 was not significantly induced following $X$. citri infiltration in transgenic Hamlin compared with inoculated control plants or water-inoculation of plants (Fig. 7B). In contrast, the gene expression of CsWRKY22 and CsPRI was significantly up-regulated at 24 hai in transgenic plants FLS2-H5 and H6 (Fig. 7C and D). No obvious gene upregulation was observed in control plants or transgenic plant FLS2-H9, which has low NbFLS2 expression (Fig. 7). This indicates that $C s W R K Y 22$ and $C s P R 1$ genes were upregulated only after NbFLS2 perception of flagellin from $X$. citri.

\section{DISCUSSION}

Our earlier studies showed that flagellin from $X$. citri, ' $C a$. L. asiaticus', and ' $C a$. L. solanacearum' can induce PAMP responses and elevate the expression of genes associated with PTI by transient expression in $N$. benthamiana. In this study, we investigated whether heterologous expression of $N b F L S 2$ in citrus can increase resistance to canker. We expressed the flagellin receptor FLS2 from $N$. benthamiana in Hamlin sweet orange and Carrizo citrange. Transgenic citrus expressing NbFLS2 showed increased ROS production that correlated with enhanced citrus canker resistance and defense-related gene activation, indicating that heterologous expression of $N b F L S 2$ is functional and can activate downstream citrus gene expression. We demonstrated that endogenous citrus FLS2 genes have low expression in citrus and exhibit no or low levels of ROS production in response to the flg $22_{X c c}$. We showed that the expression of CsWRKY22 and CsPRI was upregulated only after $X$. citri infection in transgenic plants with high expression of NbFLS2. Our results suggest that heterologous overexpression of a functional FLS2 receptor followed by challenge with a compatible pathogen can activate the plant immunity pathway, which may lead to broad-spectrum disease resistance.

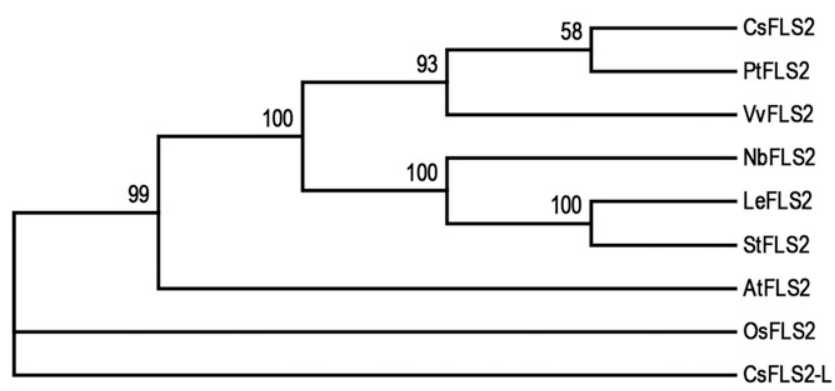

Fig. 2. Phylogenetic tree showing the relationship between FLS2 orthologs. The protein sequences included Arabidopsis AtFLS2 (GenBank accession number: NM_124003), tomato LeFLS2 (GenBank number: XP_004233092), N. benthamiana NbFLS2 (Niben.v4.2.Scf14580), Vitis vinifera VvFLS2 (GenBank number: XP_002272319), potato StFLS2 (GenBank number: XP_6365570), poplar PtFLS2 (GenBank number: XP_002305701), rice OsFLS2 (GenBank number: CHA68341), citrus FLS2 homologs CsFLS2 (GenBank number: XP 006478775), and CsFLS2-L (orange1.1 g000859m at the Joint Genome Institute Phytozome database). The MEGA6.06 program was used to construct the tree with the maximum likelihood method. The bootstrap consensus tree was inferred from 1,000 replicates and bootstrap values were indicated next to the branches. Fewer than $75 \%$ alignment gaps, missing data, and ambiguous bases were allowed at any position. There were a total of 1,182 positions in the final dataset. 
One of the earliest cellular responses following successful pathogen recognition is a rapid and transient oxidative burst (Wojtaszek, 1997; Torres et al. 2006). We demonstrated increased ROS production in NbFLS2 transgenic citrus, indicating that the FLS2 receptor has the ability to interact with flg $22_{X c c}$ and activate PTI responses. The nonhost defense response in the $A$. thaliana and $X$. citri interaction is apparent through ROS production and the expression of defense genes (An and Mou 2012). Recently, it was demonstrated that PTI was induced more significantly in the canker-resistant variety 'Nagami' kumquat compared with susceptible 'Duncan' grapefruit (Shi et al. 2014). ROS production was also shown to be correlated to the expression of defense-related genes and the reduction of canker development in the sour orange seedling screening (Y. Duan, unpublished). In our experiments, no significant ROS production was detected in canker-susceptible nontransgenic sweet orange Hamlin exposed to flg22 $X c c$. Though some nontransgenic Carrizo seedlings showed slightly higher ROS production compared with nontransgenic Hamlin, it was relatively low compared with transgenic plants expressing NbFLS2. It is interesting that two ROS peaks were observed in transgenic Carrizo plant C57 (Fig. 4B). In $N$. benthamiana, typically only a single sharp ROS peak is induced by flg22 within 50 min after flg22 treatment; however, there is a report of a second broad weaker peak occurring 2 to $6 \mathrm{~h}$ after the first ROS peak returned to basal level (Segonzac et al. 2011). It has been suggested that a second ROS peak is associated with plant cell death when challenged with hypersensitive response-inducing pathogens (Ren et al. 2002). Further investigations are underway for this interesting transgenic Carrizo plant C57. Our results suggest that strengthening plant innate immune system via overexpressing a heterologous PAMP receptor is a promising method by which to enhance citrus disease resistance.

PTI can serve as the first layer of protection against nonpathogenic and pathogenic microbes. Plant reduced-function mutants associated with PAMP pathways, such as A. thaliana and $N$. benthamiana FLS2 mutants, are more susceptible to nonadapted strains that normally don't cause disease as well as to virulent Pseudomonas syringae (Zipfel et al. 2004). The PAMP receptor EFR from $A$. thaliana was expressed in both $N$. benthamiana and tomato plants and enhanced resistance to several plant pathogens from different genera. In addition, enhanced resistance has been previously reported for transgenic plants expressing genes associated with the plant defense system (Bouwmeester et al. 2014; Fagoaga et al. 2011). Xa21 transgenic citrus plants showed enhanced resistance to citrus
A

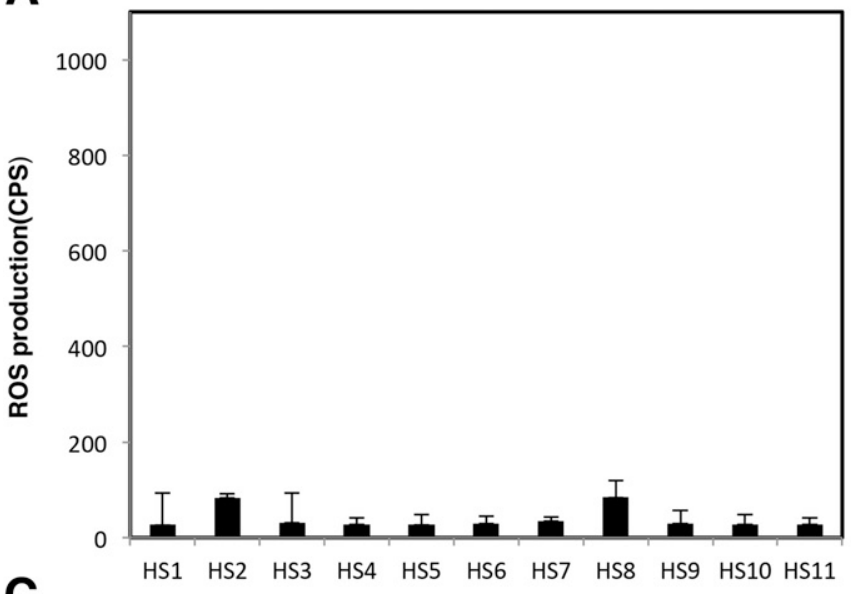

C

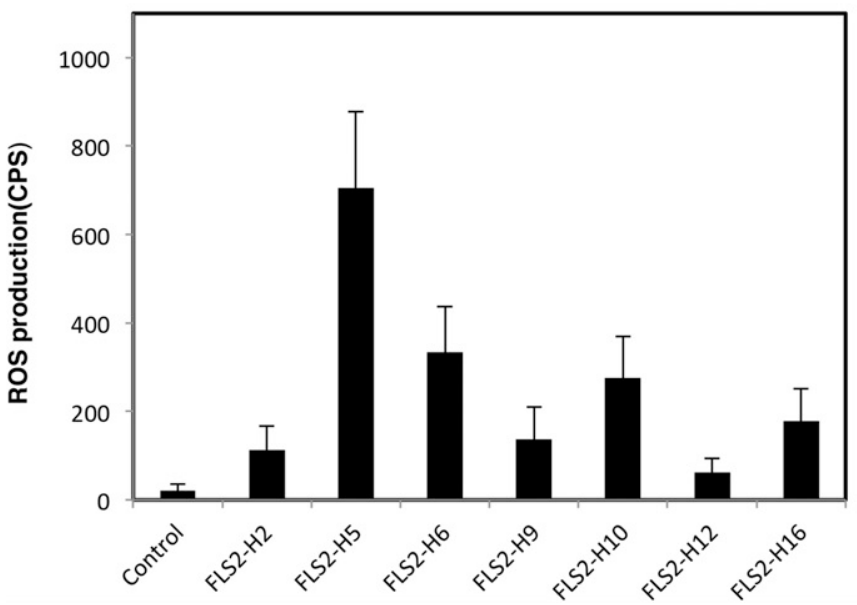

B
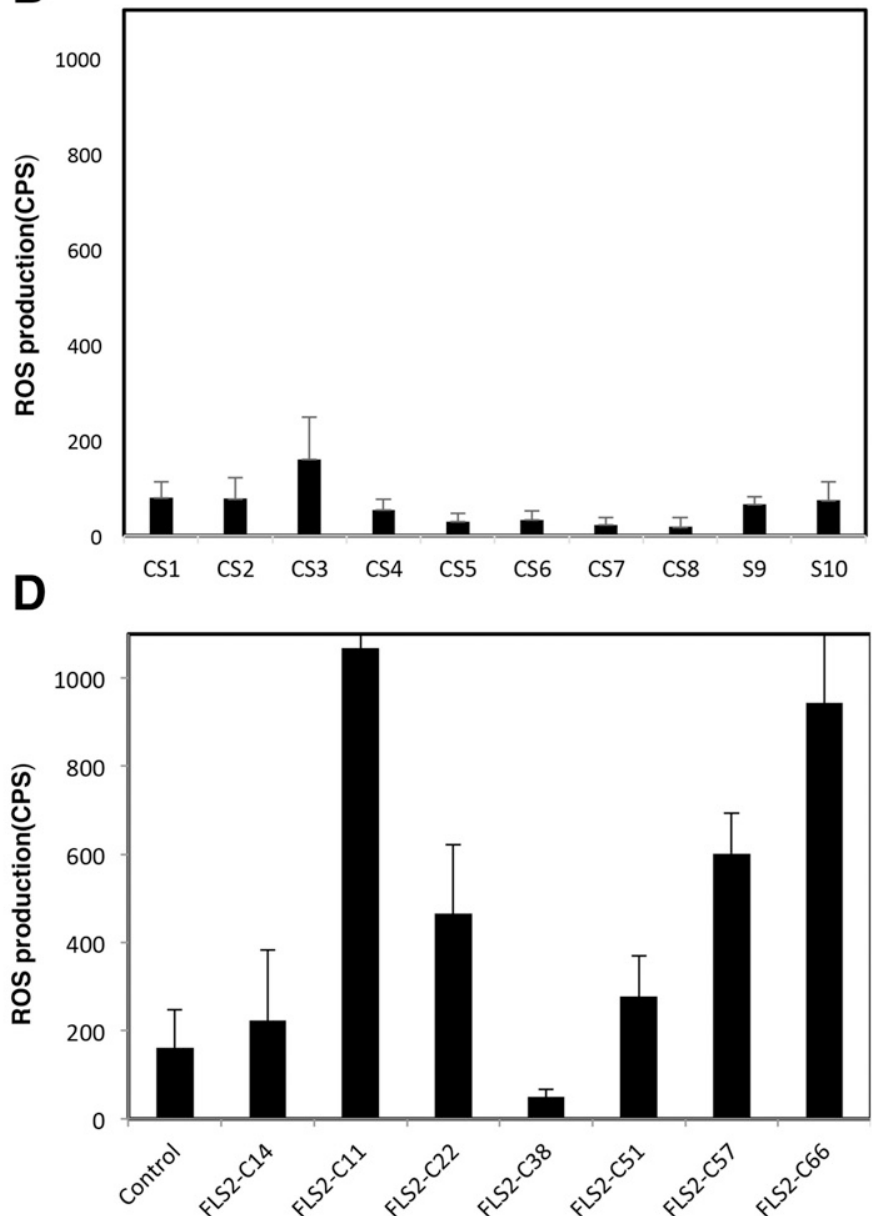

Fig. 3. Comparison of reactive oxygen species (ROS) bursts in nontransgenic citrus seedlings and transgenic plants. Eight leaf discs from each seedling and transgenic plant were floated on water overnight in a 96 -well plate at room temperature. Prior to ROS measurement, water was replaced with $100 \mu 1$ of assay solution. The assay was monitored about 40 min after addition of $100 \mu \mathrm{l}$ of assay solution $\left(17 \mathrm{mM}\right.$ lumino, $1 \mu \mathrm{M}$ horseradish peroxidase, and $0.1 \mu \mathrm{M}$ flg $\left.22_{X c c}\right)$ and was detected with chemiluminescence probe Luminol. A, Hamlin seedlings, B, Carrizo seedlings, C, transgenic Hamlin expressing NbFLS2, D, transgenic Carrizo expressing NbFLS2. NbFLS2 polymerase chain reaction-negative plants were used as control plants in C and D. Bars represent peak luminescence reading across $40 \mathrm{~min}$ of each sample. Error bars represent standard deviation from eight leaf discs. CPS $=$ count per second. 
canker, indicating that the $\mathrm{Xa21}$ resistance gene from rice is functional in citrus (Mendes et al. 2010). Transgenic citrus expressing A. thaliana NPR1 protein, a SA signal transducer from A. thaliana, showed enhanced disease resistance to citrus canker (Zhang et al. 2010). Transgenic citrus expressing citrus MAPK increased ROS generation and resistance when challenged with $X$. citri (de Oliveira et al. 2013).

Our study demonstrates that endogenous FLS2 homologs from citrus share low homology with $F L S 2$ from $N$. benthamiana and are normally expressed at low levels. Following flg $22_{X c c}$ challenge, no significant ROS production was detected in cankersusceptible nontransgenic sweet orange (Fig. 3). This indicates that FLS2 homologs from canker-susceptible varieties are insensitive to $X$. citri flagellin or that there is a weak interaction between the FLS2 receptors and $X$. citri flagellin. Similar results were reported previously with reduced gene induction and weak ROS production in canker-susceptible citrus genotypes treated with flg22 $2_{X c c}$ (Shi et al. 2014). It is not clear why there is a weak interaction between citrus FLS2 homologs and $X$. citri flagellin. CsFLS2 shares a typical FLS2 receptor structure with a ligandbinding ectodomain, a transmembrane domain, one domain containing $28 \mathrm{LRR}$, and contains the amino acids reported to be critical. However, CsFLS2-L contains several more LRR compared with reported functional FLS2 orthologs and lacks several critical amino acids, including Ser-938, which are important for the PAMP-mediated immunity pathway (Cao et al. 2013). Though $C s F L S 2$ expression was detected by RT-qPCR in Hamlin, full-length $C s F L S 2$, which was identified in NCBI Valencia sweet orange data, was not identified in the $C$. sinensis genome sequence from the JGI Phytozome database. Further investigation is needed to clarify whether CsFLS2 is present in all Citrus sinensis varieties.

Overexpression of NbFLS2 in transgenic citrus increases canker resistance following spray inoculation but not infiltration. It is not surprising that no obvious difference was observed for canker development by infiltration, because studies have shown that PAMPs and FLS2-mediated immunity against pathogenic bacteria is associated, in part, with closure of stomata (Melotto et al. 2006). Under natural conditions, $X$. citri infects citrus leaves through wounds or stomata. However, infiltration of bacteria with a syringe will bypass the first steps of the natural infection process. An A. thaliana FLS2 mutant with reduced function did show more severe disease symptoms compared with wild-type plants after spraying $P$. syringae DC3000 onto leaf surfaces (Zipfel et al. 2004). Studies showed that canker resistance in the mandarin 'Okitsu' was bypassed using leaf infiltration (Favaro et al. 2014). Recently, flg22-induced oxidative burst and FLS2 signaling activation of MPK3 and MPK6 were shown to be essential for control of stomatal closure in disease resistance (Mersmann et al. 2010; Montillet et al. 2013). Spray inoculation more closely resembles the natural infection process of $X$. citri through stomata, which allows flagellin or flg22 $2_{X c c}$ to interact with FLS2 receptors and activate PTI. Resistant and susceptible citrus genotypes have been reported to have differences in stomatal characteristics and stomatal response (apertures) following exposure to $X$. citri (Wang et al. 2011).

The constitutive overexpression of defense-related genes in plants can potentially lead to either necrosis, reduced growth, or both (Aldwinckle and Malnoy 2009). Transgenic Arabidopsis constitutively overexpressing EDS5 showed activation of pathogen-related genes and enhanced virus disease resistance, however the transgenic plants were severely dwarfed (Ishihara et al. 2008). In addition, Arabidopsis overexpressing NDR1 had enhanced bacterial disease resistance and also led to PRI constitutive expression, spontaneous lesions, and stunting (Coppinger et al. 2004). In our experiments, no developmental or growth defects were observed in transgenic citrus plants expressing $N b F L S 2$. We showed no constitutive $C s P R 1$ gene expression in our transgenic plants expressing $N b F L S 2$. Instead our results suggest that flagellin must be present to trigger FLS2 to activate $C s W R K Y 22$ and $C s P R 1$ gene expression (Fig. $7)$. We determined that the expression of the PTI marker gene $C s W R K Y 22$ was highly induced $24 \mathrm{~h}$ after infiltration with $X$. citri. The induction of $C s W R K Y 22$ was previously reported in canker-resistant cultivar 'Nagami' kumquat following
A

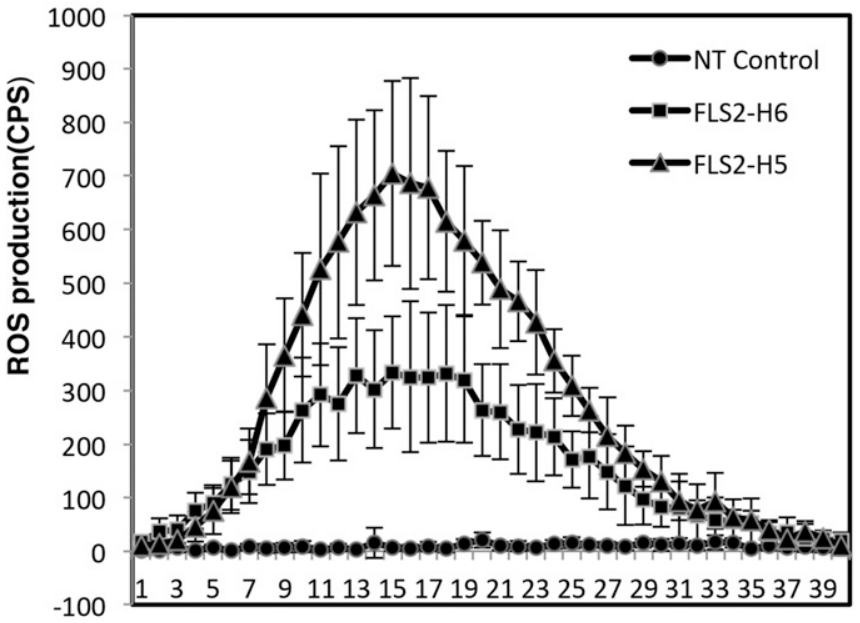

Time after flg22 treatment(minutes)
B

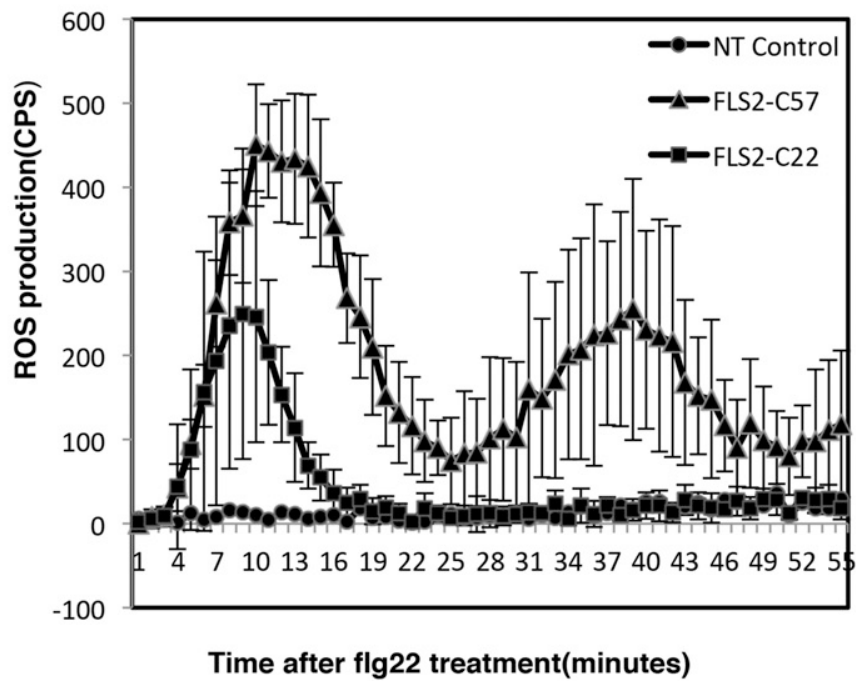

Fig. 4. Reactive oxygen species (ROS) assay for transgenic citrus expressing NbFLS2. Eight leaf discs from each seedling and transgenic plant were floated on water overnight in a 96-well plate at room temperature. Prior to ROS measurement, water was replaced with $100 \mu \mathrm{l}$ of assay solution. Assays were monitored at 40 or 60 min and were detected with chemiluminescence probe Luminol. A, Transgenic Hamlin plants H5 and H6 showed typical ROS response. No ROS response was observed with the flg $22_{X c c}$-treated $N b F L S 2$ polymerase chain reaction (PCR)-negative plant. B, Transgenic Carrizo plant C57 showed two peaks of ROS production and transgenic plant C22 showed only one peak. No ROS response was observed with the flg22 $2_{X c}$-treated $N b F L S 2$ PCR-negative plant. Error bars represent the standard deviation from eight leaf discs. CPS: count per second. 
flg22 $\mathrm{Xcc}_{\mathrm{cc}}$ treatment (Shi et al. 2014). In conclusion, we showed that heterologous expression of NbFLS2 in citrus can increase ROS production and activate PTI and defense-associated gene expression. We demonstrated that the expression level of NbFLS2 correlated with canker suppression as well as ROS production level. Our results indicate that a functional flagellin perception system exists in citrus. It remains of interest to investigate whether citrus FLS2 orthologs interact with flagellin of $X$. citri or ' $C a$. Liberibacter asiaticus' and whether overexpression of citrus FLS2 can increase disease resistance. Furthermore, transgenic citrus trees expressing $N b F L S 2$ are under further investigation regarding their resistance to citrus greening disease.

\section{MATERIALS AND METHODS}

Citrus seed preparation and germination.

Seeds were extracted from mature fruits of Hamlin sweet orange $[C$. sinensis $(\mathrm{L}$.) Osbeck] and Carrizo citrange $[C$. sinensis (L.) Osbeck $\times$ Poncirus trifoliata (L.) Raf.] and were treated with pectinase overnight. The seed coats were removed and the surface of seeds were sterilized by soaking in ETOH. The

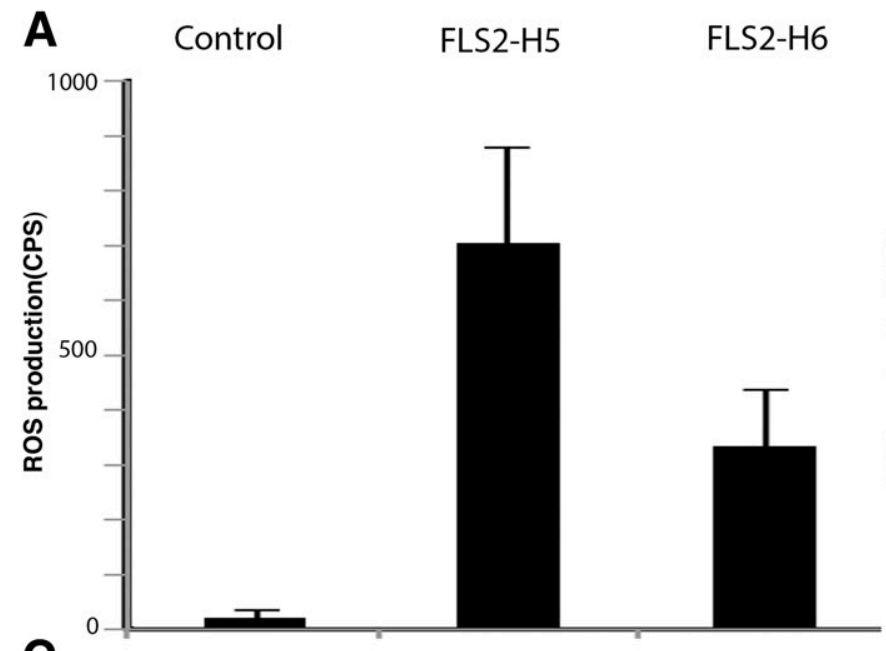

C

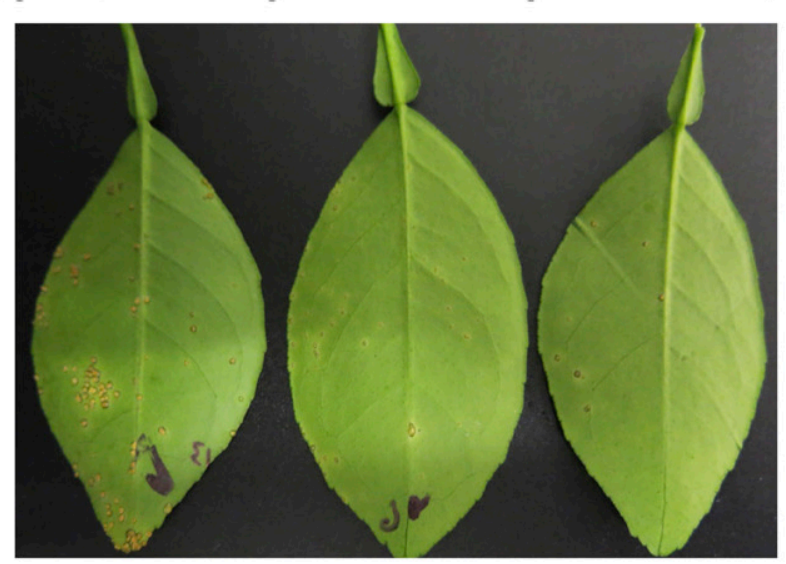

B

Control

FLS2-C66

FLS2-C11

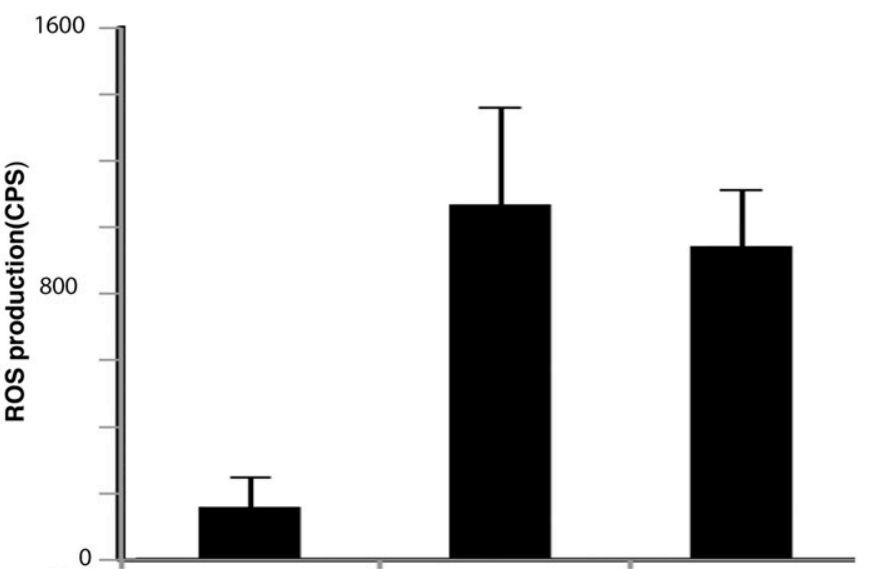

D

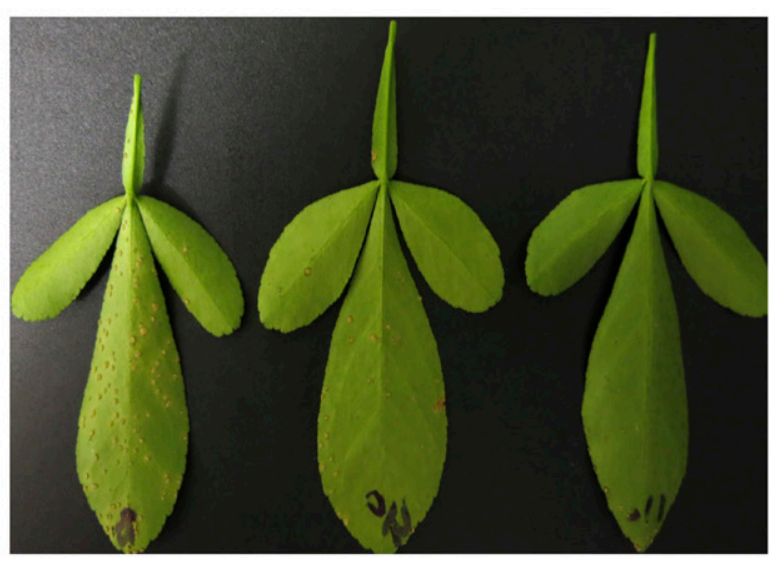

E

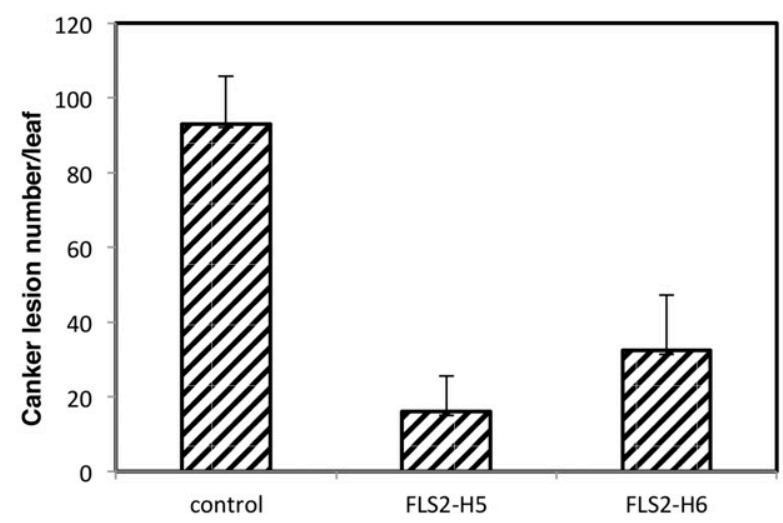

$\mathbf{F}$

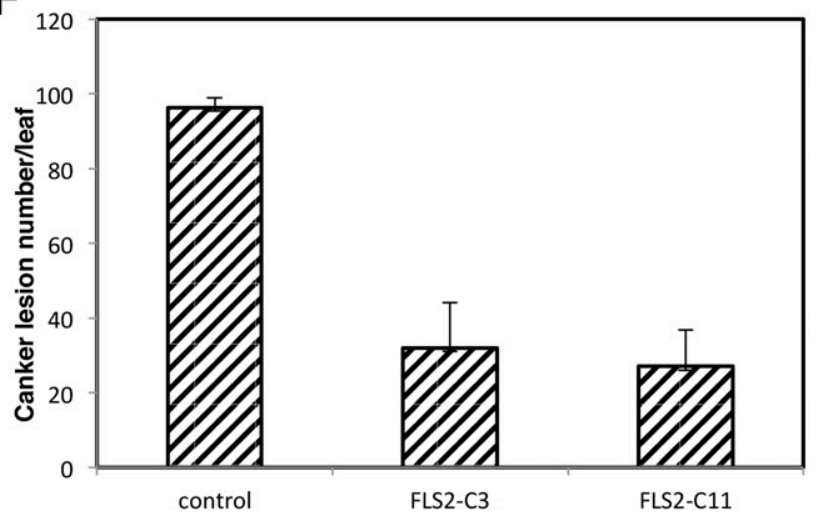

Fig. 5. Comparison of reactive oxygen species (ROS) production, citrus canker symptoms, and canker lesions in leaves of a NbFLS2 polymerase chain reaction-negative plant as control and transgenic plants. A, ROS production in transgenic Hamlin and control; B, ROS production in transgenic Carrizo and control. C, Canker symptoms in transgenic Hamlin and control; D, canker symptoms in transgenic Carrizo and control. E, Canker lesion numbers in transgenic Hamlin and control; F, canker lesion numbers in transgenic Carrizo and control. Xamthomonas citri was applied by spray inoculation and was evaluated at 30 days postinoculation. Bars represent means of three inoculated leaves. Two replicated plants of each transgenic parent plant were tested with similar results. 
seeds were then treated with sodium hypochlorite solution (10\%) for $10 \mathrm{~min}$, followed by rinses with sterile distilled water. The seeds were planted in Magenta jars containing Murashige Skoog (MS) solid medium and were incubated in the dark at $27^{\circ} \mathrm{C}$ for 2 to 3 weeks. Germinated seedlings with a height of 12 to $15 \mathrm{~cm}$ were transferred to a 16-h photoperiod growth chamber for 10 days. After this period, the epicotyls of the seedlings were cut for Agrobacterium-mediated transformation experiments.

\section{Gene cloning and vector construction.}

RNA was isolated from leaves of $N$. benthamiana and cDNA was obtained by reverse transcriptase (Invitrogen, Carlsbad, CA, U.S.A.). Primers for NbFLS2 cDNA amplification were designed containing Sma1 and Spec 1 restriction sites (Table 1). The PCR reactions were performed in a thermal cycler under the following conditions: $3 \mathrm{~min}$ at $95^{\circ} \mathrm{C}$ for the first denaturation, followed by 26 cycles of $30 \mathrm{~s}$ at $95^{\circ} \mathrm{C}, 45 \mathrm{~s}$ at $53^{\circ} \mathrm{C}$, and $4 \mathrm{~min}$ at $68^{\circ} \mathrm{C}$, plus a final extension of $10 \mathrm{~min}$ at $68^{\circ} \mathrm{C}$.
A

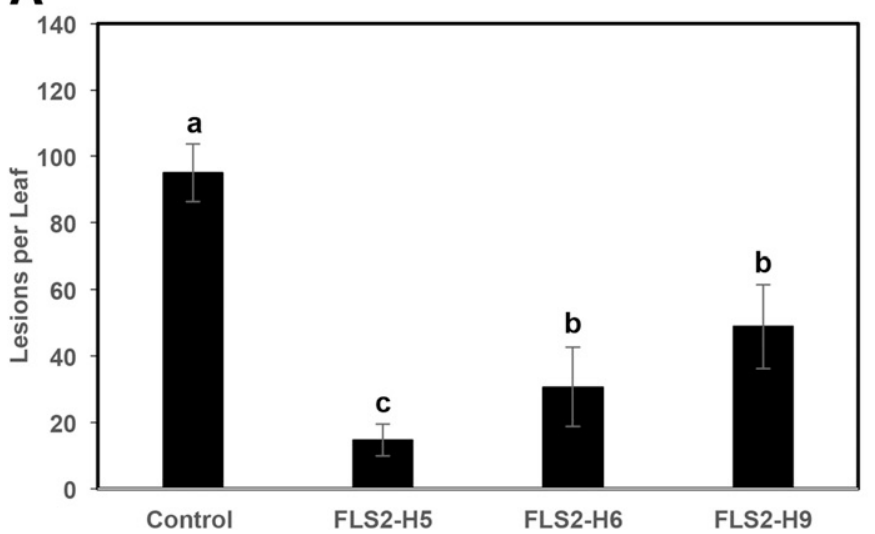

B

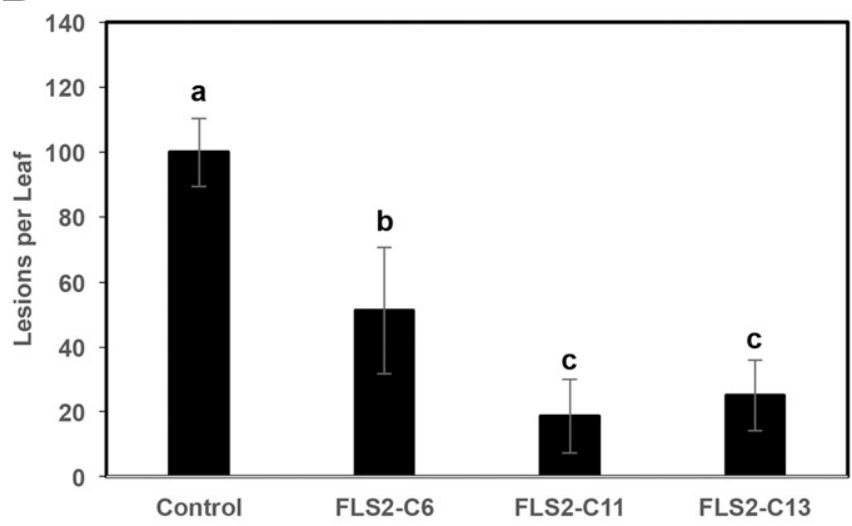

Fig. 6. Canker lesions incited by Xanthomonas citri spray inoculation in transgenic plants and control plants. Lesions were surveyed 25 days after inoculation. Two replicated plants from each transgenic plant were sprayed at each time point and the experiment was repeated three times. Statistical analysis was performed with one-way analysis of variance and Tukey's posttest with a $P$ value $<0.05$. Within each group (A or B), columns with different letters are significantly different at the $P<0.05$ level. Each column represents the mean and error bars are the standard deviation of the mean $(n=6)$. A, Nontransgenic control versus transgenic Hamlin plants expressing NbFLS2. B, Nontransgenic control versus transgenic Carrizo plants expressing NbFLS2.

A

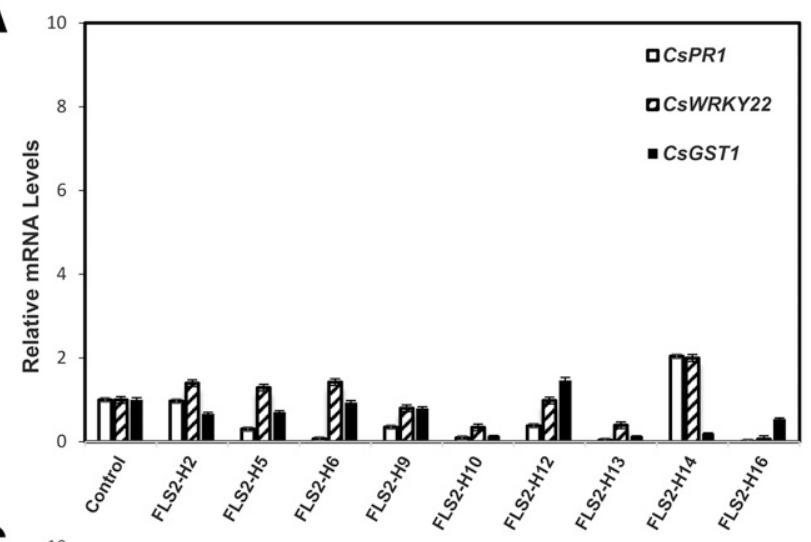

C

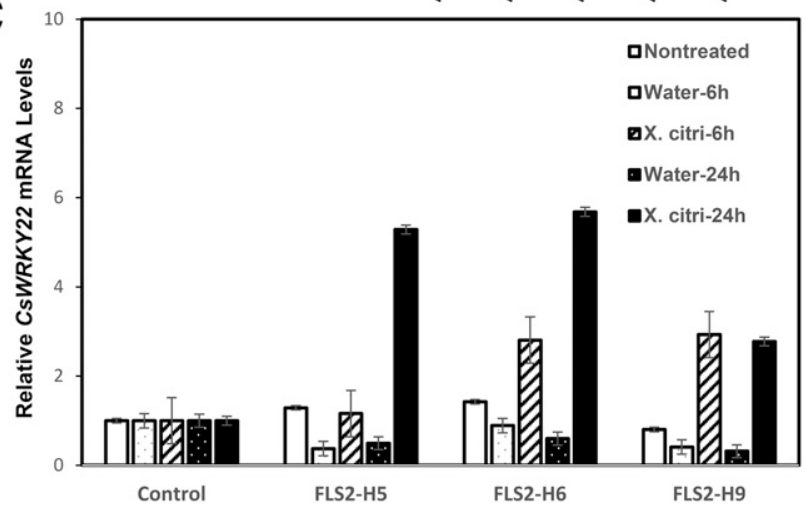

B

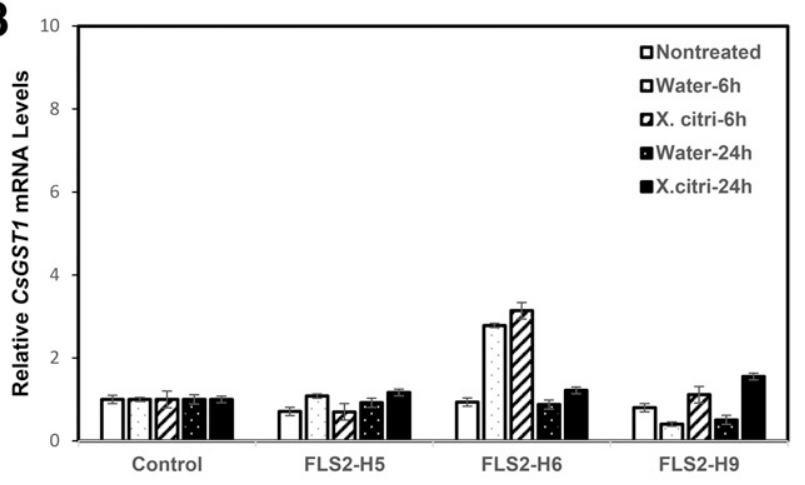

D

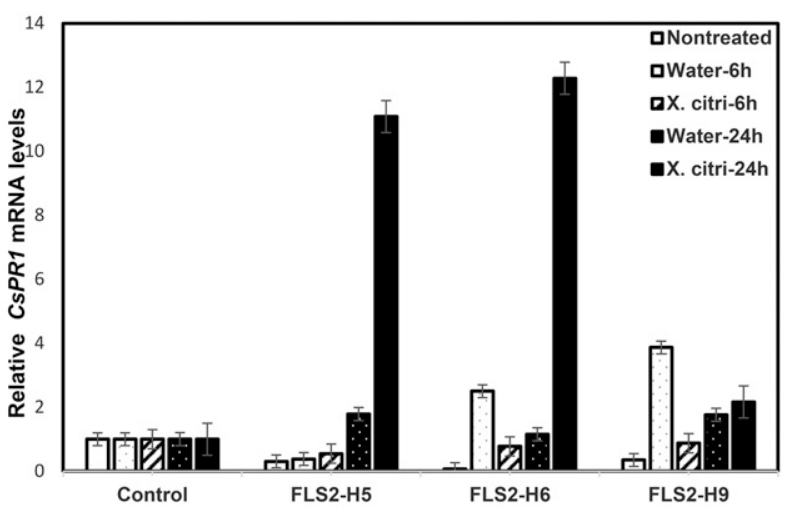

Fig. 7. Gene expression in transgenic Hamlin plants expressing NbFLS2 and control plants. A, Comparison of the expression of CsPR1, CsWRKY22, and CsGST1 in transgenic Hamlin expressing NbFLS2 and control plants without Xanthomonas citri inoculation. B, C, and D, CsGST1, CsWRKY22, and CsPR1 expression in transgenic Hamlin FLS2-H5, H6, H9, and control plants without X. citri inoculation, 6 and 24 h following water or X. citri infiltration. Bars represent relative mRNA fold change of $C s P R 1, C s W R K Y 22$, and $C s G S T 1$ in transgenic plants and control plants. The samples were normalized against the citrus GAPC2 gene. Data are showed as average fold induction compared with control plants from three independent experiments. 
PCR products were purified and were digested with Sma1 and Spec1 and were ligated into pBinPlus/ARS containing a double $35 \mathrm{~S}$ promoter from Cauliflower mosaic virus and a Nos terminator. The plasmid was sequenced, confirmed, and designated as pBinARS-NbFLS2. Agrobacterium tumafaciens EHA105 was transformed with pBinARS-NbFLS2 by electroporation. Transformed A. tumefaciens EHA105 cells were confirmed by PCR and were used for citrus transformation.

\section{Genetic transformation and plant regeneration.}

Epicotyl segments $(0.8$ to $1.0 \mathrm{~cm})$ were cut from in vitro germinated seedlings and were incubated with Agrobacterium carrying pBinARS-NbFLS2 (optical density at $600 \mathrm{~nm}\left(\mathrm{OD}_{600}\right)$ of about 0.7 to 0.8 ) for $20 \mathrm{~min}$, were blotted dry, and were transferred to coculture medium (CM1) supplemented with benzylaminopurine (BAP) at $1.0 \mathrm{mg}$ per liter for 3 days $\left(24^{\circ} \mathrm{C}\right.$, in the dark). After the coculture period, explants were transferred to MSB1 selection medium supplemented with BAP, kanamycin, and cefotaxime $(1.0,100$, and $500 \mathrm{mg}$ per liter, respectively). Cultures were incubated in the dark $\left(27^{\circ} \mathrm{C}\right)$ for 2 to 3 weeks and were then transferred to a 16 -h photoperiod at $27 \pm 1^{\circ} \mathrm{C}$.

Kanamycin-resistant shoots were carefully excised from the explants and roots were induced on MS medium with the addition of $1 \mu \mathrm{M}$ spermidine (Mendes et al. 2011). Welldeveloped plantlets were transferred to container pots with soil-less mix and were kept in a greenhouse.

\section{Molecular analysis of transformed plants.}

Genomic DNA was isolated from leaves of independent transgenic plants and control plants by Qiagen kit and were evaluated by PCR. Primers were designed based on the sequence of NbFLS2 and Nos terminator regions (Table 1). Transgenic plants containing the target gene were used for further analysis. RNA was extracted using TRIzol reagent according to the manufacture's instruction (Sigma-Aldrich, St. Louis). Total RNA was quantified using the Nanodrop (Thermo Fisher Scientific, Wilmington, DE, U.S.A.) and was treated with RQ1 RNase-free DNase (Promega Corp, Madison, WI, U.S.A.). DNase-treated RNA (approximately $1.5 \mu \mathrm{g}$ ) from control and transgenic leaves was used to synthesize first-strand cDNA with $0.5 \mu \mathrm{g}$ of oligo (dT) primer and $1 \mu \mathrm{l}$ of SuperScript III reverse transcriptase in a $20-\mu 1$ reaction (Invitrogen). A negative control without the reverse transcription was performed to verify the absence of genomic DNA contamination.

RT-qPCR was performed with Bright Green (Sigma-Aldrich) in triplicate, using an ABI7500 thermal cycler (Applied Biosystems, Foster City, CA, U.S.A.). The 25- $\mu$ l amplification reactions contained the following: $12.5 \mu \mathrm{l}$ of Bright Green PCR master mix, $250 \mathrm{nM}$ of each forward and reverse primer, and $2.0 \mu \mathrm{l}$ of $1: 10$ diluted cDNA template. The following protocol was used: $95^{\circ} \mathrm{C}$ for $2 \mathrm{~min}, 40$ cycles of $30 \mathrm{~s}$ for denaturation at $95^{\circ} \mathrm{C}$, and $30 \mathrm{~s}$ for extension at $60^{\circ} \mathrm{C}$. Primers for $N b F L S 2$, CsFLS2, and CsFLS2-L are listed in Table 1. The citrus gene glyceraldehyde-3-phosphate dehydrogenase C2 (GAPC2) was amplified and was used to normalize the values as an internal control (Mafra et al. 2012). To compare transcript levels, a ratio of relative gene expression is calculated from the cycle threshold $\left(2^{\Delta \mathrm{Ct}}\right)$ values of a sample versus a reference sample that had the lowest $2^{\Delta \mathrm{Ct}}$ in the tested samples, $\Delta \mathrm{Ct}=\mathrm{Ct}$ (internal control) - Ct (target gene). The qPCR reactions were set up in triplicate and were repeated twice with similar results.

\section{Sequence alignment and phylogenic analysis.}

Protein sequence alignment analysis was performed using SV CLC Sequence program (Qiagen, Boston). Phylogenic trees were constructed using the MEGA6 program (Tamura et al.
2013) with the maximum likelihood method (Whelan and Goldman, 2001) and bootstrap value 1,000.

\section{ROS production assay.}

The flg22 $2_{X c}$ peptide (QRLSSGLRINSAKDDAAGLAIS) from $X$. citri was synthesized by GenScript (Piscataway, NJ, U.S.A.). Young tender citrus leaves from transgenic plants and nontransgenic control plants were used for ROS assays. Eight leaf discs from each sample were taken, using a $0.5 \mathrm{~cm}$ diameter cork borer, and were floated on water overnight in a 96-well plate at room temperature. Prior to ROS measurement, water was replaced with $100 \mu \mathrm{l}$ of assay solution $(17 \mathrm{mM}$ luminol, $1 \mu \mathrm{M}$ horseradish peroxidase, and $0.1 \mu \mathrm{M}$ flg $22_{X c c}$ ) (Hao et al. 2014). Luminescence was measured using a LUMIstar microplate luminometer (BMG, Cary, NC, U.S.A.). Each plate was measured over a period of 40 or 60 min after addition of assay solution. Similarly, leaf discs were taken from nontransgenic Hamlin and Carrizo seedlings and the ROS assay was performed. The assay was repeated twice. Controls lacking flg22 $2_{X c c}$ were included for each plant. Data were analyzed using Optima software (BMG, Cary, NC, U.S.A.).

\section{Evaluation of resistance to $X$. citri in transgenic plants.}

Transgenic plants and nontransgenic control plants of Hamlin and Carrizo were selected for disease resistance evaluation. The infiltration experiments were performed on independent transgenic plants and nontransgenic control plants. $X$. citri was grown overnight in Luria Bertani liquid and were centrifuged and the pellet was diluted, to an $\mathrm{OD}_{600}=0.3$, in autoclaved tap water. Serial dilution plating was used to determine bacterial population. Three young fully expanded leaves of each plant were infiltrated with $X$. citri at $10^{4}, 10^{5}, 10^{6}$, and $10^{7} \mathrm{CFU}$ per milliliter. Plants were also spray-inoculated with a $10^{6} \mathrm{CFU}$ per milliliter suspension of $X$. citri with the addition of $0.02 \%$ silwet77. Three young fully expanded leaves were spray-inoculated on each plant. Disease severity was evaluated frequently after inoculation. Images were taken 4 weeks after spray inoculation. Three independent experiments were performed with similar results.

\section{Bacterial growth determined by qPCR.}

Bacterial growth in leaves was assessed by qPCR with the DNA isolated from leaf discs of infiltrated leaves in the zone of inoculation at $2 \mathrm{~h}$ and 3, 6, 9, and 12 dai. Fresh tissues were homogenized for genomic DNA extractions by Qiagen kit and were used for qPCR analyses. The presence of the $p t h A$ gene was determined using gene-specific primers VM3 and VM4, designed for $X$. citri quantification (McCollum et al. 2011). Primers were added at $0.5 \mu \mathrm{M}$ in a $25-\mu \mathrm{l}$ reaction with $12.5 \mu \mathrm{l}$ of $2 \times$ Bright Green master mix reagent (Sigma-Aldrich) and $2 \mu \mathrm{l}$ of DNA template (about $100 \mathrm{ng}$ ). Real time PCR was performed as described above. Based on a standard curve, the formula Copy Number ${ }_{(X c c, p t h A)}=10^{(38.3-\mathrm{ct}) / 3.56}$ was used for quantification of $X$. citri (Stover and McCollum 2011). At each time point, samples were determined from three technical replicates and each experiment was done in duplicate. Control sampling was performed on leaf discs taken from nontransformed plants.

\section{Gene expression analysis induced by $X$. citri.}

Gene expression induced by $X$. citri was evaluated in leaves of noninoculated, water-infiltrated, and $X$. citri-infiltrated plants at 6 and $24 \mathrm{~h}$ after infiltration. Primer pairs are listed in Table 1. Primers for CsGST1, CsWRKy22, and CsPR1 were designed according to Citrus sinensis genomic data from NCBI, with Loc102614737, Loc102612567, and Loc102623146 respectively. CsGSTIand CsWRKy 22 were examined because both 
genes were induced in canker-resistant citrus varieties by $X$. citri flg22 (Shi et al. 2014). In addition, CsPRl was upregulated in 'Ponkan' mandarin by Xylella fastidiosa infection (Rodrigues et al. 2013). The pellet of $X$. citri was suspended in sterile tap water and was adjusted to $3 \times 10^{5} \mathrm{CFU} / \mathrm{ml}$ for gene expression analysis. The bacterial suspension was infiltrated into three whole leaves of each transgenic and control plant by infiltration of the abaxial leaf surface with a needleless syringe. The leaves of transgenic and control plants were also mock-inoculated with sterile tap water. Three leaf discs were collected from infiltration zones of each leaf, using a round punch (6 $\mathrm{mm}$ in diameter), as independent biological replicates. RNA isolation, cDNA synthesis, and RT-qPCR were performed as described above. The gene expression level was normalized against the internal control CsGAPC2. The relative mRNA expression levels were normalized with noninoculated plant samples.

\section{ACKNOWLEDGMENTS}

We thank E. Cochrane, Y. Avila, and M. Sewell for their excellent technical assistance. Funding was provided by the Citrus Research and Development Foundation. We also thank G. Martin from Cornell University for $N$. benthamiana FLS2 information. Mention of trade names or commercial products in this article is solely for the purpose of providing specific information and does not imply recommendation or endorsement by the U. S. Department of Agriculture.

\section{LITERATURE CITED}

Afroz, A., Chaudhry, Z., Rashid, U., Ali, G. M., Nazir, F., Iqbal, J., and Khan, M. R. 2011. Enhanced resistance against bacterial wilt in transgenic tomato (Lycopersicon esculentum) lines expressing the Xa21 gene. Plant Cell Tissue Organ Cult. 104:227-237.

Aldwinckle, H., and Malnoy, M. 2009. Plant regeneration and transformation in the Rosaceae. Transgenic Plant J. 3:1-39.

An, C., and Mou, Z. 2012. Non-host defense response in a novel ArabidopsisXanthomonas citri subsp. citri pathosystem. PLoS One 7:e31130.

Asai, T., Tena, G., Plotnikova, J., Willmann, M. R., Chiu, W. L., GomezGomez, L., Boller, T., Ausubel, F. M., and Sheen, J. 2002. MAP kinase signalling cascade in Arabidopsis innate immunity. Nature 415: 977-983.

Boller, T., and Felix, G. 2009. A renaissance of elicitors: Perception of microbe-associated molecular patterns and danger signals by patternrecognition receptors. Annu. Rev. Plant Biol. 60:379-406.

Bouwmeester, K., Han, M., Blanco-Portales, R., Song, W., Weide, R., Guo, L. Y., van der Vossen, E. A., and Govers, F. 2014. The Arabidopsis lectin receptor kinase LecRK-I.9 enhances resistance to Phytophthora infestans in Solanaceous plants. Plant Biotechnol. J. 12:10-16.

Brunings, A. M., and Gabriel, D. W. 2003. Xanthomonas citri: Breaking the surface. Mol. Plant Pathol. 4:141-157.

Cao, Y., Aceti, D. J., Sabat, G., Song, J., Makino, S., Fox, B. G., and Bent, A. F. 2013. Mutations in FLS2 Ser-938 dissect signaling activation in FLS2-mediated Arabidopsis immunity. PLoS Pathog. 9:e1003313.

Chakravarthy, S., Velásquez, A. C., Ekengre, S. K, Collmer, A., and Martin, G. B. 2010. Identification of Nicotiana benthamiana genes involved in pathogen-associated molecular pattern-triggered immunity. Mol. PlantMicrobe Interact. 23:715-726.

Che, F. S., Nakajima, Y., Tanaka, N., Iwano, M., Yoshida, T., Takayama, S., Kadota, I., and Isogai, A. 2000. Flagellin from an incompatible strain of Pseudomonas avenae induces a resistance response in cultured rice cells. J. Biol. Chem. 275:32347-32356.

Chinchilla, D., Bauer, Z., Regenass, M., Boller, T., and Felix, G. 2006. The Arabidopsis receptor kinase FLS2 binds flg22 and determines the specificity of flagellin perception. Plant Cell 18:465-476.

Coppinger, P., Repetti, P. P., Day, B., Dahlbeck, D., Mehlert, A., and Staskawicz, B. J. 2004. Overexpression of the plasma membranelocalized NDR1 protein results in enhanced bacterial disease resistance in Arabidopsis thaliana. Plant J. 40:225-237.

de Oliveira, M. L., de Lima Silva, C. C., Abe, V. Y., Costa, M. G., Cernadas, R. A., and Benedetti, C. E. 2013. Increased resistance against citrus canker mediated by a citrus mitogen-activated protein kinase. Mol. Plant-Microbe Interact. 26:1190-1199.

Dunning, F. M., Sun, W., Jansen, K. L., Helft, L., and Bent, A. F. 2007. Identification and mutational analysis of Arabidopsis FLS2 leucine-rich repeat domain residues that contribute to flagellin perception. Plant Cell 19:3297-3313.

Fagoaga, C., Rodrigo, I., Conejero, I., Hinarejos, C., Tuset, J. J., Arnau, J., Pina, J. A., Navarro, L., and Peña, L. 2011. Increased tolerance to Phytophthora citrophthora in transgenic orange plants constitutively expressing a tomato pathogenesis related protein PR-5. Mol. Breeding 7: $175-185$.

Favaro, M. A., Micheloud, N. G., Roeschlin, R. A., Chiesa, M. A., Castagnaro, A. P., Vojnov, A. A., Gmitter, F. G., Jr., Gadea, J., Rista, L. M., Gariglio, N. F., and Marano, M. R. 2014. Surface barriers of mandarin 'Okitsu' leaves make a major contribution to canker disease resistance. Phytopathology 104:970-976.

Felix, G., Duran, J. D., Volko, S., and Boller, T. 1999. Plants have a sensitive perception system for the most conserved domain of bacterial flagellin. Plant J. 18:265-276.

Gómez-Gómez, L., Bauer, Z., and Boller, T. 2001. Both the extracellular leucine-rich repeat domain and the kinase activity of FSL2 are required for flagellin binding and signaling in Arabidopsis. Plant Cell 13: 1155-1163.

Gottwald, T. R., Graham, J. H., Civerolo, E. L., Barrett, H. C., and Hearn, C. J. 1993. Differential host-range reaction of citrus and citrus relatives to citrus canker and citrus bacterial spot determined by leaf mesophyll susceptibility. Plant Dis. 77:1004-1009.

Hao, G., Pitino, M., Ding, F., Lin, H., Stover, E., and Duan, Y. 2014. Induction of innate immune responses by flagellin from the intracellular bacterium, 'Candidatus Liberibacter solanacearum'. BMC Plant Biol. 14:211.

Ishihara, T., Sekine, K. T., Hase, S., Kanayama, Y., Seo, S., Ohashi, Y., Kusano, T., Shibata, D., Shah, J., and Takahashi, H. 2008. Overexpression of the Arabidopsis thaliana EDS5 gene enhances resistance to viruses. Plant Biol Stuttg 10:451-461.

Jones, J. D., and Dangl, J. L. 2006. The plant immune system. Nature 444: 323-329.

Lacombe, S., Rougon-Cardoso, A., Sherwood, E., Peeters, N., Dahlbeck, D., van Esse, H. P., Smoker, M., Rallapalli, G., Thomma, B. P., Staskawicz, B., Jones, J. D., and Zipfel, C. 2010. Interfamily transfer of a plant pattern-recognition receptor confers broad-spectrum bacterial resistance. Nat. Biotechnol. 28:365-369.

Leach, J. E., Vera Cruz, C. M., Bai, J., and Leung, H. 2001. Pathogen fitness penalty as a predictor of durability of disease resistance genes. Annu. Rev. Phytopathol. 39:187-224.

Mafra, V., Kubo, K. S., Alves-Ferreira, M., Ribeiro-Alves, M., Stuart, R. M., Boava, L. P., Rodrigues, C. M., and Machado, M. A. 2012. Reference genes for accurate transcript normalization in citrus genotypes under different experimental conditions. PLoS One 7:e31263.

McCollum, G., Stange, R., Albrecht, U., Bowman, K., Niedz, R., and Stover, E. 2011. Development of a qPCR technique to screen for resistance to Asiatic citrus canker. Acta Hortic. 892:173-181.

McDonald, B. A., and Linde, C. 2002. Pathogen population genetics, evolutionary potential, and durable resistance. Annu. Rev. Phytopathol. 40:349-379.

Melotto, M., Underwood, W., Koczan, J., Nomura, K., and He, S. Y. 2006. Plant stomata function in innate immunity against bacterial invasion. Cell 126:969-980.

Mendes, A. F. S., Cidade, L. C., Otoni, W. C., Soares-Filho, W. S., and Costa, M. G. C. 2011. Role of auxins, polyamines and ethylene in root formation and growth in sweet orange. Biol. Plant. 55:375-378.

Mendes, B. M. J., Cardoso, S. C., Boscariol-Camargo, R. L., Cruz, R. B., Mourão Filho, F. A. A., and Bergamin Filho, A. 2010. Reduction in susceptibility to Xanthomonas axonopodis pv. citri in transgenic Citrus sinensis expressing the rice Xa21 gene. Plant Pathol. 59:68-75.

Mersmann, S., Bourdais, G., Rietz, S., and Robatzek, S. 2010. Ethylene signaling regulates accumulation of the FLS2 receptor and is required for the oxidative burst contributing to plant immunity. Plant Physiol. 154: 391-400

Montillet, J. L., Leonhardt, N., Mondy, S., Tranchimand, S., Rumeau, D., Boudsocq, M., Garcia, A. V., Douki, T., Bigeard, J., Laurière, C., Chevalier, A., Castresana, C., and Hirt, H. 2013. An abscisic acidindependent oxylipin pathway controls stomatal closure and immune defense in Arabidopsis. PLoS Biol. 11:e1001513.

Mueller, K., Bittel, P., Chinchilla, D., Jehle, A. K., Albert, M., Boller, T., and Felix, G. 2012. Chimeric FLS2 receptors reveal the basis for differential flagellin perception in Arabidopsis and tomato. Plant Cell 24:2213-2224.

Ren, D., Yang, H., and Zhang, S. 2002. Cell death mediated by MAPK is associated with hydrogen peroxide production in Arabidopsis. J. Biol. Chem. 277:559-565.

Robatzek, S., Bittel, P., Chinchilla, D., Köchner, P., Felix, G., Shiu, S. H., and Boller, T. 2007. Molecular identification and characterization of the 
tomato flagellin receptor LeFLS2, an orthologue of Arabidopsis FLS2 exhibiting characteristically different perception specificities. Plant Mol. Biol. 64:539-547.

Rodrigues, C. M., de Souza, A. A., Takita, M. A., Kishi, L. T., and Machado, M. A. 2013. RNA-Seq analysis of Citrus reticulata in the early stages of Xylella fastidiosa infection reveals auxin-related genes as a defense response. BMC Genomics 14:676.

Segonzac, C., Feike, D., Gimenez-Ibanez, S., Hann, D. R., Zipfel, C., and Rathjen, J. P. 2011. Hierarchy and roles of pathogen-associated molecular pattern-induced responses in Nicotiana benthamiana. Plant Physiol. 156:687-699.

Shi, Q. C., Febres, V. J., Jones, J. B., and Moore, G. A. 2014. Responsiveness of different citrus genotypes to the Xanthomonas citri ssp. citri-derived pathogen-associated molecular pattern (PAMP) flg22 correlates with resistance to citrus canker. Mol. Plant Pathol. doi:10.1111/mpp.12206.

Stover, E. W., and McCollum, T. G. 2011. Levels of Candidatus Liberibacter asiaticus and Xanthomonas citri in diverse citrus genotypes and relevance to potential transmission from pollinations. HortScience 46:854-857.

Sun, Y., Li, L., Macho, A. P., Han, Z., Hu, Z., Zipfel, C., Zhou, J. M., and Chai, J. 2013. Structural basis for flg22-induced activation of the Arabidopsis FLS2-BAK1 immune complex. Science 342:624-628.

Tai, T. H., Dahlbeck, D., Clark, E. T., Gajiwala, P., Pasion, R., Whalen, M. C., Stall, R. E., and Staskawicz, B. J. 1999. Expression of the Bs2 pepper gene confers resistance to bacterial spot disease in tomato. Proc. Natl. Acad. Sci. U.S.A. 96:14153-14158.

Takai, R., Isogai, A., Takayama, S., and Che, F. S. 2008. Analysis of flagellin perception mediated by flg22 receptor OsFLS2 in rice. Mol. Plant-Microbe Interact. 21:1635-1642.

Tamura, K., Stecher, G., Peterson, D., Filipski, A., and Kumar, S. 2013. MEGA6: Molecular evolutionary genetics analysis version 6.0. Mol. Biol. Evol. 30:2725-2729.

Thilmony, R. L., Chen, Z., Bressan, R. A., and Martin, G. B. 1995. Expression of the tomato Pto gene in tobacco enhances resistance to Pseudomonas syringae pv. tabaci expressing avrPto. Plant Cell 7:1529-1536.

Torres, M. A., Jones, J. D. G., and Dangl, J. L. 2006. Reactive oxygen species signaling in response to pathogens. Plant Physiol. 141:373-378.
Trdá, L., Fernandez, O., Boutrot, F., Héloir, M. C., Kelloniemi, J., Daire, X., Adrian, M., Clément, C., Zipfel, C., Dorey, S., and Poinssot, B. 2014. The grapevine flagellin receptor VvFLS2 differentially recognizes flagellin-derived epitopes from the endophytic growth-promoting bacterium Burkholderia phytofirmans and plant pathogenic bacteria. New Phytol. 201:1371-1384.

Tripathi, J. N., Lorenzen, J., Bahar, O., Ronald, P., and Tripathi, L. 2014. Transgenic expression of the rice Xa21 pattern-recognition receptor in banana (Musa sp.) confers resistance to Xanthomonas campestris pv. musacearum. Plant Biotechnol. J. 12:663-673.

Wang, Y., Fu, X., Liu, J., and Hong, N. 2011. Differential structure and physiological response to canker challenge between 'Meiwa' kumquat and 'Newhall' navel orange with contrasting resistance. Sci. Hortic. (Amsterdam) 128:115-123.

Whelan, S., and Goldman, N. 2001. A general empirical model of protein evolution derived from multiple protein families using a maximumlikelihood approach. Mol. Biol. Evol. 18:691-699.

Wojtaszek, P. 1997. Oxidative burst: An early plant response to pathogen infection. Biochem. J. 322:681-692.

Zhang, X., Francis, M. I., Dawson, W. O., Graham, J. H., Orbovic, V., Triplett, E. W., and Mou, Z. L. 2010. Over-expression of the Arabidopsis NPRl gene in citrus increases resistance to citrus canker. Eur. J. Plant Pathol. 128:91-100.

Zipfel, C., Robatzek, S., Navarro, L., Oakeley, E. J., Jones, J. D., Felix, G., and Boller, T. 2004. Bacterial disease resistance in Arabidopsis through flagellin perception. Nature 428:764-767.

Zou, H., Gowda, S., Zhou, L., Hajeri, S., Chen, G., and Duan, Y. 2012. The destructive citrus pathogen, 'Candidatus Liberibacter asiaticus' encodes a functional flagellin characteristic of a pathogen-associated molecular pattern. PLoS One 7:e46447.

\section{AUTHOR-RECOMMENDED INTERNET RESOURCE}

Joint Genome Institute (JGI) Phytozome database:

http://phytozome.jgi.doe.gov/pz/portal.html 